\title{
A pesquisa em políticas educacionais no Brasil: de que estamos tratando?
}

\author{
Research into educational policies in Brazil: what \\ are we talking about?
}

\section{La investigación en políticas educativas en Brasil: ¿qué estamos tratando?}

\author{
Ângelo Ricardo de Souza*
}

\begin{abstract}
Resumo: Este artigo apresenta e analisa parte da produção acadêmica brasileira sobre políticas educacionais. Para tanto, toma os 215 trabalhos aprovados/apresentados nas sessões anuais do Grupo de Trabalho 5 (Estado e Política Educacional) da Associação Nacional de Pesquisa e Pós-Graduação em Educação (ANPED), entre 2000 e 2011. O texto focaliza, em uma primeira parte, mais aprofundadamente, os temas e objetos de estudo, com o intuito de mapear o que os pesquisadores do campo têm priorizado em suas investigações; na segunda parte, o artigo apresenta e brevemente discute as formas como os pesquisadores têm lidado com tais objetos. Metodologicamente, a investigação tomou a leitura dos títulos, palavras-chave e resumo (quando havia) e do texto dos artigos de maneira transversal, isto é, inicialmente lendo toda a introdução e as conclusões. Havendo necessidade de maior aprofundamento para se destacarem os objetos, tomou-se o texto na sua íntegra para a leitura. As conclusões mostram que a pesquisa em políticas educacionais no Brasil toma dominantemente a (não) ação do Estado diante das demandas da população por educação na conjuntura atual e, a partir disto, evidenciam um conjunto de desafios postos para o campo de pesquisa.
\end{abstract}

Palavras-chave: Políticas Educacionais. Produção acadêmica. ANPED.

Abstract: This article presents and analyzes part of the Brazilian academic production
on educational policies. The study comprises the 215 papers presented at the
Research Committee 5 (State and Educational Policy) annual sessions of the National
Association for Education Research and Post-Graduation (ANPED), between 2000
and 2011. The first part of the text focuses on themes and subjects of study, in order
to map what researchers have prioritized in their investigations; in the second part, the
article presents and briefly discusses the ways in which researchers have dealt with such
subjects. Methodologically, this investigation carried out the reading of titles, keywords,
and abstract (when there was one) and the text of articles in a transversal way, that is,
initially reading the entire introduction and conclusions. When this procedure was not

* Professor da Universidade Federal do Paraná (UFPR). E-mail: < angelo@ufpr.br> 
enough to highlight the research issues, the whole text was read. Results show that research in the educational policy field in Brazil focuses mainly on the State (non) action regarding the demands of the population for education in the current context and, from this, highlight a number of challenges posed to the research field.

Keywords: Educational policies. Academic production. National Association of PostGraduation and Educational Research - ANPED.

Resumen: En este artículo presenta y analiza parte de la producción académica brasileña acerca de las políticas educativas. Para esto, se tomaron 215 ponencias presentadas en las sesiones anuales del Grupo de Trabajo 5 (Estado y Política Educativa) de la Asociación Nacional de Investigación y Posgrado en educación (ANPED) entre 2000 y 2011. En la primera parte, el texto se centra en los temas y objetos de estudio, con el fin de mapear lo que los investigaciones han priorizado en sus investigaciones; y en la segunda parte, el artículo presenta y discute brevemente las maneras en que los investigadores han tratado con tales objetos. Metodológicamente, la investigación se diseñó a partir de la lectura de los títulos, palabras clave y resumen (cuando existía) y el texto de los artículos en un modo transversal, es decir, en principio leyendo la introducción y las conclusiones. Cuando era necesario, para una mayor profundización para resaltar objetos, se examinó el texto en su totalidad. Los resultados muestran que la investigación en políticas educativas en Brasil toma predominantemente la (no) acción estatal sobre las demandas de la población para la educación en la coyuntura actual y, a partir de esto, destacan una serie de desafíos para el campo de investigación.

Palabras clave: Políticas educativas. Producción académica. ANPED - Asociación Nacional de Investigación y Posgrado en educación.

\section{Introdução}

Este artigo tem por objetivo identificar e analisar os temas tomados pelas pesquisas em políticas educacionais no Brasil, com vistas a contribuir com uma leitura sobre os possíveis problemas e limitações na produção acadêmica e no desenvolvimento deste campo de pesquisa. Parece não haver um consenso pleno sobre o que é/são o/s objeto/s de investigação neste campo, ao menos no Brasil. A maior evidência disto advém da diversidade de temas que é tratada pelos trabalhos publicados/apresentados nos espaços acadêmicos do campo em tela. Contudo, como se fará ver mais adiante, há uma linha agregadora nesta diversidade.

Assim, neste estudo buscou-se justamente produzir um levantamento acerca da produção acadêmica no campo de pesquisa em políticas educacionais, 
a partir da leitura dos trabalhos apresentados no Grupo de Trabalho (GT) 5 - Estado e Política Educacional, da Associação Nacional de Pesquisa e PósGraduação em Educação - ANPEd, nas reuniões anuais de 2000 a 2011. Tomou-se o ano de 2000 como ponto de partida, pois é a partir desta data que os trabalhos aprovados/apresentados na sessão anual estão disponíveis no sítio da associação na internet.

A organização temática, as abordagens e a análise desses trabalhos foram organizadas em dois passos: o primeiro focaliza diretamente os temas de estudo, com o intuito de mapear o que os pesquisadores do campo têm priorizado em suas investigações; o segundo busca apresentar e brevemente discutir as metodologias de análise e pesquisa do campo, isto é, as formas como os pesquisadores têm lidado com tais temas, ou, ainda, como têm tratado dos problemas de pesquisa. A prevalência deste artigo recai sobre o primeiro passo, especialmente porque ele é o objeto indicado no seu título.

Para tanto, metodologicamente, tomou-se a leitura dos títulos, palavraschave e resumo (quando havia) e do texto dos artigos de maneira transversal, isto é, inicialmente lendo toda a introdução (ou equivalente ${ }^{1}$ ) e as conclusões. Havendo necessidade de maior aprofundamento para se destacarem os objetos, tomou-se o texto na sua íntegra para a leitura.

\section{O que se pesquisa em Políticas Educacionais no Brasil?}

Os temas ${ }^{2}$ a seguir elencados não seguem nenhuma classificação prévia, ao contrário, a partir da leitura dos textos, constituiu-se um quadro no qual os diversos temas iam sendo informados à proporção que surgiam. Ao final desse processo, o quadro foi analisado, e ajustamentos foram realizados, aproximando temas e objetos. Por exemplo, no ajustamento, as pesquisas que tratavam de políticas de Educação Infantil, Ensino Fundamental e Ensino Médio foram todas agrupadas em "Etapas e Modalidades". Do contrário se teria um infindável número de classificações: no limite, teríamos 320 linhas, pois que eram 320 temas específicos derivados dos 215 trabalhos analisados. O número de temas específicos é maior do que o de trabalhos, porque há trabalhos que tratam de mais de um tema. Contudo, essas especificidades acabaram agrupadas em 17 temas mais amplos, como mostra a tabela 1.

\footnotetext{
${ }^{1}$ Nem sempre havia nos textos analisados uma divisão didática que indicasse a "Introdução" ou as "Conclusões". Nesses casos, avançou-se na leitura até o ponto em que o objeto/problema investigado e as formas tomadas no trabalho ficavam evidentes.

${ }^{2}$ Optou-se por se referir a temas porque nem sempre se tem a precisão suficiente para se avaliar o objeto de estudo de um dado artigo (infelizmente, isto acontece!). Mas, especialmente, porque o agrupamento promovido entre diversos objetos acabou organizando-os dominantemente em temas de investigação.
} 
Essa tabela também mostra que há um predomínio do tema da Gestão da Educação na pesquisa em políticas educacionais, respondendo por $1 / 4$ dos estudos do campo. Em alguma medida, mesmo outras pesquisas distribuídas em outras classificações também poderiam ser encaixadas como pesquisas sobre gestão, pois que, mesmo sem precisar ou aprofundar adequadamente, tratam a gestão como o campo de operação da política (SOUZA, 2012). As discussões mais recentes sobre esta temática tomam dominantemente aspectos do planejamento educacional (PAR, Planos Municipais de Educação, etc.) e da democratização da gestão, seja no âmbito dos sistemas de ensino, quanto no escolar, sendo que o predomínio ocorre neste último caso.

Os estudos mais teóricos em políticas educacionais aparecem em segundo lugar, com pouco mais de $13 \%$, e demonstram que os investigadores do campo ainda tomam discussões mais conceituais para seus estudos. Porém, ainda que tal evidência possa, de partida, contestar uma eventual crítica ao crescente empirismo na pesquisa em políticas educacionais, tais estudos teóricos também podem ser expressão de ensaios acadêmicos e não necessariamente de pesquisas. Esta questão, complexa e controversa, relaciona-se com o debate sobre o quanto os pesquisadores em políticas educacionais dão preferência por fazer a política ao invés de estudá-la. Ou seja, alguns desses trabalhos expressam mais a verve crítico-política do pesquisador, que é cidadão, militante, etc., à conjuntura, ou ao governo de plantão, do que uma análise da política. Em uma frase, lembram mais análises políticas antes de análises da política (FIGUEIREDO; FIGUEIREDO, 1986).

Os estudos sobre Políticas para Etapas e Modalidades de ensino são o terceiro grupo predominante, como algo próximo a 11\%. É possível que sejam mesmo mais do que esses 36 trabalhos, pois, com a forma de organização da ANPEd em grupos de trabalho, há GT com enfoque na Educação Infantil, no Ensino Fundamental, no Ensino Médio, no Ensino Superior, na Educação de Jovens e Adultos, na Educação Especial. Isso quer dizer que as pesquisas que tomam aquelas etapas ou modalidades como objeto de investigação podem tender a encaminhar seus artigos para os GT específicos, ainda que, em alguns casos, haja uma abordagem acerca das políticas educacionais para a etapa ou modalidade em questão. Contudo, este levantamento não buscou nas bases dos demais GT da ANPEd a confirmação dessa hipótese, menos ainda uma estimativa quantitativa da interface temática entre os GT.

Os trabalhos sobre políticas e reformas na/sobre a educação equivalem a quase $10 \%$ do conjunto analisado e estão localizados dominantemente mais na primeira metade do período investigado, possivelmente pela influência que a conjuntura da política (educacional) tem/teve sobre os pesquisadores, uma vez que as resultantes das reformas do Estado e da educação dos anos 1990 
no Brasil provocaram estudos cujos resultados estão também aqui expressos. O fato de na segunda metade do período tais estudos não constarem de maneira tão evidente tem relação, ao que parece, com a ausência de novas leituras sobre os movimentos e consequências daquelas reformas uma década (e mais) após a sua constituição. Isso, todavia, não quer dizer que as reformas se encerraram. É possível que parte da pesquisa sobre Gestão, especialmente aquela que toma a discussão sobre o planejamento, assim como da pesquisa sobre Programas e Ações, esteja ocupando esse espaço, contudo, agora com foco mais pontual em fenômenos especificamente localizados temporal ou geograficamente, ao invés de macroabordagens, como aquelas anteriores, as quais buscavam compreender as articulações entre a política educacional nacional e o contexto político e econômico nacional e internacional.

Estes últimos, os estudos sobre Programas e Ações da/na política educacional, respondem pelo quinto posto, com 9,4\%. Trata-se de trabalhos que tomam objetos específicos da política educacional (PDE-Escola; Programa Salto para o Futuro; Parâmetros Curriculares Nacionais; Programa Nacional da Alimentação Escolar; entre outros). Nesses casos, há uma aparente preocupação em se buscar avaliar os resultados de uma dada política, mas nem sempre considerando a análise da proposta da política diante dos resultados por ela alcançados (análise da eficácia). Ainda resiste uma abordagem de cobrança sobre o que a política deveria prever/propor, mesmo com a tentativa de se avaliarem os seus resultados.

Os textos sobre Avaliação e sobre Financiamento da Educação dividem o sexto posto, com 4,4\%. Ambos os temas são provocados pelo forte incremento da política educacional nessas áreas após as reformas educacionais mencionadas. A (re)criação do sistema nacional de avaliação, de um lado, e da política de fundos, de outro, são fatores fortemente indutores dessas pesquisas. Mas os trabalhos correm por caminhos um tanto diversos. Os estudos sobre políticas de avaliação versam, em boa proporção, sobre a insuficiência dos modelos adotados para a avaliação de sistemas de ensino no Brasil, ou, ainda mais, sobre a razoabilidade de sua própria existência. Já os trabalhos que tomam o financiamento da educação como preocupação buscam promover uma avaliação das resultantes das políticas de financiamento, por muitos autores denominadas de impactos. Esta leitura, em particular, é muito importante, pois sem tal preocupação torna-se muito difícil dimensionar a possível tradução da política como texto na política enquanto efeitos (BALL, 2006a).

Mais recentemente, no GT 5 da ANPEd, observa-se um incremento dos estudos sobre Trabalho Docente. É possível, mais uma vez, que sejam muitos outros trabalhos sobre políticas para os trabalhadores da educação (e não apenas para os docentes), além desses 12 aqui mencionados, pois é razoável supor que 
alguns tantos estejam em outros GT, especialmente neste caso no de Trabalho e Educação. De qualquer sorte, são estudos que colocam o trabalhador docente no contexto da política, ou seja, não parece haver neste levantamento estudos (sociológicos, por exemplo) sobre o trabalho docente em si.

Tem-se visto, salutarmente, um conjunto de estudos que tomam o próprio campo como objeto de investigação. Os 11 (3,3\%) trabalhos aqui denominados de Estado da Arte não são, efetivamente, estados do conhecimento exaustivos. São, majoritariamente, leituras sobre a produção acadêmica sobre objetos específicos das políticas educacionais. Ainda assim, contribuem grandemente para análises como a que este trabalho busca fazer, pois auxiliam na identificação de escolhas, tendências do pensamento, abordagens, etc. utilizadas pelos pesquisadores em políticas educacionais.

Neste levantamento, foram separados os estudos sobre Conselhos, dada a sua relevância quantitativa (10), mas, grosso modo, poderiam ser encaixados na temática Gestão. As abordagens aqui são diversas, seja tomando conselhos municipais, seja no âmbito escolar, os estudos têm como eixo, quase sempre, a questão dos limites e possibilidades desses organismos em ampliar a transparência, o controle social e a gestão democrática da educação/escola.

Os estudos sobre políticas curriculares se distribuem ao longo de todo o período e representam $2,7 \%$ do conjunto. Como, novamente, há um GT especializado na matéria (Currículo), é razoável supor que há mais estudos sobre políticas curriculares aprovados/apresentados na ANPEd.

Com os mesmos 2,7\% dos trabalhos, a temática da Municipalização é tratada ao longo de todo o período. A tônica desses estudos recai sobre a municipalização no Ensino Fundamental, dadas as tensões próprias aos (des)acordos de oferta desta etapa da Educação Básica pelos estados e municípios.

A legislação educacional é tratada em oito estudos que tomam os processos de produção de normas, além da efetividade ou eficácia de determinadas leis, ou melhor, se se trata de legislação que vai ao encontro das demandas sociais, ou, de outro lado, a leitura é sobre o alcance das metas e objetivos propostos pelas peças legais. Esses estudos se articulam com a temática sobre o direito à educação, sendo que há trabalhos que se encontram nos dois grupos. Mas o direito à educação também é abordado na perspectiva crítica de análise de demandas por educação, ou seja, com foco nas possíveis tensões que sofre o Estado para o reconhecimento ou ampliação do direito à educação. Assim, a constituição da demanda ou pressão sobre a agenda política é também aqui tratada.

Os estudos sobre Organismos Internacionais totalizam seis, e parte deles analisa tais instituições no contexto das reformas educacionais, portanto estão tratados naquele outro grupo. Todavia, há estudos que analisam documentos 
desses organismos buscando as compreensões e noções que a entidade dá/tem em relação a determinado tópico da política educacional ou a determinado conceito, por exemplo, à gestão educacional ou à ideia de cidades educadoras.

Por fim, o levantamento evidenciou a existência de trabalhos que tomam a História da Política Educacional e/ou de Intelectuais. A pesquisa sobre a história da política pode estar também representada no GT História da Educação; então aqui se tem um problema, como anteriormente se verificou também nas interfaces entre os diversos GT da ANPED, mas neste caso a questão é outra. É seguro que os estudos sobre políticas de etapas e modalidades de ensino assim como sobre políticas curriculares, etc. são trabalhos em políticas educacionais, isto é, versam sobre a conjuntura da política educacional. Já os estudos sobre história da política educacional e mesmo os sobre intelectuais (Anísio Teixeira, Lourenço Filho) não tratam, por óbvio, da conjuntura atual. Em que medida então são estudos sobre políticas educacionais? Se o conjunto de temas elencados e as respectivas abordagens enfatizam estudos sobre a conjuntura atual, compreendida aqui como o quadro de conjunção de elementos, em momento histórico recente/atual, que se articula à situação política, econômica, social de um país ou região, então aqueles estudos em perspectiva histórica só serão estudos sobre políticas educacionais se a historicidade do fenômeno em tela se articular de maneira muito direta com a conjuntura atual. Convém ao campo, todavia, analisar melhor esta questão, especialmente se tomamos a afirmação de Ball e Mainardes (2011) de que a abordagem histórica da política educacional compõe parte dos objetos do campo.

Tabela 1 - Temas pesquisados em políticas educacionais - GT5 ANPEd (2000/2011)

\begin{tabular}{c|c|c}
\hline TEMA & $\mathrm{N}^{\circ}$ & $\%$ \\
\hline Gestão da Educação (de sistema, escolar, gestão democrática) & 81 & 24,6 \\
\hline Teorias e conceitos & 43 & 13,1 \\
\hline Etapas e modalidades & 36 & 10,9 \\
\hline Reformas (do Estado, Educacional) & 32 & 9,7 \\
\hline Programas e Ações & 31 & 9,4 \\
\hline Avaliação (Políticas de avaliação; Avaliação em larga escala) & 14 & 4,3 \\
\hline Financiamento da educação & 14 & 4,3 \\
\hline Trabalho docente & 12 & 3,6 \\
\hline Estado da arte/Pesquisa em Política Educacional & 11 & 3,3 \\
\hline Conselhos (Municipal; Escolar; Controle social) & 10 & 3,0 \\
\hline Políticas curriculares & 9 & 2,7 \\
\hline Municipalização & 9 & 2,7 \\
\hline Legislação educacional & 8 & 2,4 \\
\hline & & continua
\end{tabular}


conclusão

\begin{tabular}{c|c|c}
\hline TEMA & $\mathrm{N}^{\mathrm{o}}$ & $\%$ \\
\hline Organismos internacionais & 6 & 1,8 \\
\hline Demandas educacionais e direito à educação & 5 & 1,5 \\
\hline Intelectuais (da educação, da política) & 5 & 1,5 \\
\hline História da Política Educacional & 3 & 0,9 \\
\hline Total & $\mathbf{3 2 9}$ & $\mathbf{1 0 0}$ \\
\hline
\end{tabular}

Fonte: $\mathrm{O}$ autor.

Segundo Ball e Mainardes (2011), os estudos em políticas educacionais, dominantemente, ou bem são de natureza teórica sobre questões amplas do processo de formulação de políticas, abrangendo discussões sobre mudanças no papel do estado, redes de influências no processo de formulação de políticas, abordagens históricas das Políticas Educacionais (geralmente vinculadas à análise de contextos socioeconômico e político), ou bem tratam de analisar e avaliar programas e políticas educacionais específicas.

É certo que essas abordagens estão contempladas nos estudos aprovados/apresentados no GT 5 da ANPEd, inclusive com as abordagens históricas, mas a leitura desse conjunto todo indica que ele está de maneira mais ampla articulado (quase) sempre à leitura do papel/ação do Estado nas diferentes frentes educacionais e, como mencionado, na conjuntura atual. Este parece ser um achado inicial: a pesquisa em políticas educacionais no Brasil toma dominantemente a (não) ação do Estado diante das demandas da população por educação na conjuntura atual.

Porém, se há no campo trabalhos que versam sobre outros aspectos, e esses estudos são aceitos para publicação/apresentação no principal evento de pesquisa em educação no país, então há uma tensão na definição do estatuto epistemológico do próprio campo. Ou seja, ao que parece, no Brasil, quem define o que se estuda em políticas educacionais são os próprios pesquisadores que, a despeito do que se possa pretender como temas e objetos próprios, disputam a presença de suas temáticas também neste campo. Assim, mesmo com a compreensão de que a leitura conjuntural atual e a tomada da relação entre as demandas da sociedade e a (não) ação do Estado devam ser marcas dos estudos em políticas educacionais, a realidade de existência e funcionamento do campo de investigação é mais dinâmica e controversa.

Ainda assim, como destacado, este artigo trabalha com a ideia derivada da leitura empírica do campo de que a pesquisa em políticas educacionais toma a (não) ação do estado no atendimento às demandas por educação pela sociedade e, na via inversa, toma também as próprias demandas sociais como objeto de 
estudo. É diante dessas demandas que o Estado opera ou não. E a não ação do Estado é sempre uma decisão (MULLER; SUREL, 2002), ou seja, a não ação se constitui ela mesma em política, por isso o estudo da ausência de ação do Estado também se constitui em objeto de pesquisa do campo.

Assim, decorre que a análise dos processos de constituição da agenda política ou de luta por garantir alguma visibilidade a pleitos da sociedade (ou frações dela) por mais ou por melhor educação constitui objeto de preocupação da pesquisa em políticas educacionais, como destacado, por exemplo, nos trabalhos sobre direito à educação. Contudo, esta leitura nem sempre é feita no campo. Ou melhor, há poucos estudos que articulam os processos e movimentos da política diante da pressão/demanda social. Isto é, a leitura da base empírica deste levantamento sugere que a avaliação que se faz da ação do Estado nem sempre toma como referência a demanda social que gerou a própria política.

Por outro lado, parece que o campo tem melhorado a incursão na análise dos resultados da política, o que em alguma proporção tem se apresentado como estudos sobre impactos da política ou mesmo efeitos. Não são de fato, em sua maioria, estudos sobre impactos ou efeitos, e sim sobre resultados (DRAIBE, 2001). O problema, todavia, não é este. A questão é que tais resultados nem sempre são cotejados com os objetivos propostos pela própria política (análise da eficácia), e assim se perde um tanto do movimento da política, pois as questões atinentes às decisões, às implementações, às traduções da política na prática estão articuladas ao plano (sempre controverso, é verdade) definido por ela própria. Ocorre que parte da literatura que trabalha com resultados compara-os com dados de demanda que não foram nem reconhecidos pela política, cobrando-se dela ações às quais ela não se propôs, isto é, cobram a efetividade da política. A criticidade inerente a esta lógica de análise tem seu lado interessante, pois coloca em tela sempre demandas sociais que o Estado, muitas vezes, ignora ao menos parcialmente. Mas tal abordagem dificulta compreender o alcance da política e, especialmente, as variações e flutuações próprias daqueles movimentos inerentes à política, e isto acaba gerando uma pesquisa com baixa capacidade de avaliação da política.

Por isto, se se perde a leitura do movimento da política, torna-se complexo compreender as influências (para não chamar de causas) que geraram aqueles resultados. Isto tem relação com a ideia de que os produtos da política não podem ser vistos como simples resultados da intenção do governante de plantão sobre os problemas que se lhe apresentam. O que, no limite, remete à ideia de se tomar o Estado como uma arena de disputa (pelo direito à educação) - abordagem pouco presente na pesquisa aqui analisada.

Mas tal situação parece não ser um problema exclusivamente da pesquisa no Brasil. Ball (2006b, assentado em Elmore, 1996) afirma que a pesquisa em 
políticas educacionais tipicamente incorpora três conceitos distintos: a) o mais novo conjunto de ações políticas automaticamente é precedente sobre todas as outras políticas sob as quais o sistema operou; b) as políticas emanam de um nível singular do sistema educacional e incorporam uma mensagem singular sobre o que as escolas deveriam fazer de maneira diferente; c) as políticas educacionais deveriam operar mais ou menos da mesma maneira independentemente das características de sua implementação. Isto traz que tipo de consequências? Perde-se o movimento e a contradição inerentes à política. Não se pode supor o governo como um ente emblemático, coeso e coerente. Emblemático até é, mas longe de ser articulado e coerente. Com isto, as eventuais conclusões de pesquisas com tais abordagens não se sustentam muito para além do discurso ideológico.

\section{Breves anotações sobre como os pesquisadores tratam os objetos de pesquisa em políticas educacionais}

Os dados dos trabalhos aprovados pelo GT 5 da ANPEd apresentam uma pequena prevalência dos estudos empíricos ante os teóricos, todavia com predomínio mesmo daquilo que aqui foi classificado como modelo misto (entendido como estudos que articulam leituras teóricas mais gerais com análises de casos empíricos mais específicos). Esta classificação é um tanto insuficiente para tipificar a diversidade das formas dos estudos no que tange a este aspecto, mas auxiliou em um ponto importante para este trabalho, conforme segue.

O que importa registrar em relação a este aspecto da forma é que há três observações interessantes a fazer: a) a distribuição dos tipos de estudo ao longo do período é bastante equilibrada, com uma exceção mais contundente em 2007, demonstrando que há diversidade de olhares sobre os objetos do campo; b) tal diversidade é importante porque pode, em tese, proporcionar uma leitura não muito reducionista sobre o desenvolvimento das ações do Estado em dada situação/contexto/problema, posto que as questões decorrentes de leituras empíricas colocam sempre em dúvida arranjos mais gerais da política definidos na teoria e, na via inversa, macroabordagens permitem leituras panorâmicas que sempre contribuem a dar sentido aos achados a partir dos dados da realidade; c) ainda que as pesquisas empíricas não sejam exclusivamente focalizadas em questões locais ou específicas, é crescente a tomada de políticas locais nos estudos do campo, e estas preocupações decorrem do fato de que o local parece ser um espaço que tem provocado mais inquietações no investigador em políticas educacionais, porque também tem provocado mais inquietações em toda a sociedade, uma vez que, no limite, trata-se dela própria. Isto é, as pessoas residem em uma região do globo, em um país e em um estado (no caso brasileiro), mas efetivamente elas têm uma relação mais aprofundada de pertença com o 
município/localidade; logo, a pressão/demanda social se apresenta primeira e mais intensamente neste nível.

Mas, de outro lado, aparentemente não se têm articulado os estudos empíricos com modelos teóricos consolidados. Tampouco se têm articulado os estudos com outros equivalentes, com metodologias já bem desenvolvidas e testadas, especialmente no exterior, e mesmo nacionalmente, de maneira a aproximar análises de resultados.

Isso quer dizer que aquelas leituras da política educacional local podem encontrar conclusões interessantes, mas que pouco dialogam com a produção acadêmica do campo, contribuindo menos para o avanço do conhecimento.

Tabela 2 - Tipos de pesquisas em políticas educacionais - GT 5 ANPEd (2000/2011)

\begin{tabular}{c|c|c|c|c}
\hline \multirow{2}{*}{ ANO } & \multicolumn{3}{|c|}{ TIPO $^{3}$} & \multirow{2}{*}{ Total } \\
\cline { 2 - 5 } & Empírica & Mista & Teórico & 19 \\
\hline 2000 & 6 & 5 & 7 & 19 \\
\hline 2001 & 7 & 10 & 2 & 9 \\
\hline 2002 & 5 & 1 & 3 & 20 \\
\hline 2004 & 5 & 7 & 8 & 22 \\
\hline 2005 & 5 & 11 & 6 & 15 \\
\hline 2006 & 4 & 7 & 4 & 17 \\
\hline 2007 & 12 & 5 & 10 & 24 \\
\hline 2008 & 5 & 7 & 5 & 12 \\
\hline 2009 & 5 & 7 & 4 & 20 \\
\hline 2010 & 5 & 5 & 5 & 22 \\
\hline 2011 & 9 & 10 & 7 & $\mathbf{2 1 5}$ \\
\hline Total & $\mathbf{7 0}$ & $\mathbf{8 1}$ & $\mathbf{6 3}$ & \\
\hline
\end{tabular}

Fonte: $\mathrm{O}$ autor.

\section{Conclusões}

Os fenômenos próprios da política educacional (e demais políticas sociais) nem sempre expressam os conflitos a eles subjacentes (NEGT; KLUGE,

\footnotetext{
${ }^{3}$ A noção de "Tipo de Pesquisa" que aqui tomamos tem o papel de levantar questões para se compreender melhor a produção acadêmica do campo. Tal classificação é, de resto, sempre controversa, pois estudos “empíricos” têm (quase) sempre alguma sustentação teórica. Contudo, a questão aqui é a ênfase do trabalho analisado. Assim, estão registrados como estudos "empíricos" aqueles que enfatizam a análise de dados coletados da realidade social; são estudos "teóricos" aqueles que não tomam tais dados para análise, ao contrário, debruçam-se a analisar conceitos e ideias no campo das políticas educacionais; e "mistos" são os estudos que discutem tanto conceitos e ideias, como os utilizam na leitura de dados empíricos.
} 
1999). E, com isto, a tarefa da pesquisa do campo se complexifica. Todavia, a partir do levantamento e considerações feitas, parece que a agenda de pesquisa do campo está dominantemente bem articulada, ainda que com uma breve lacuna temporal, com a própria agenda da política educacional. Isto é, as demandas da sociedade por educação e as (não) respostas do Estado provocam os investigadores a tomar os temas que se encontram no epicentro dessas disputas como objetos de estudos, e isto apresenta certo delay entre a política educacional propriamente dita e os processos de investigação sobre ela, como era de se esperar, uma vez que para que dada questão da política educacional provoque o interesse dos pesquisadores, ela precisa gerar algum tipo de movimento ou resultado, o que demanda um tempo específico.

Como a política é dinâmica, complexa e controversa, e como as demandas por educação são crescentes, tem-se ampliado também, quantitativamente e na diversidade de abordagens, os estudos em políticas educacionais. Isto, quiçá, tem contribuído por não se ter ainda, no Brasil, uma definição muito precisa sobre quais são os temas de estudo deste campo, mesmo que a prioridade que lhes é dada indique que se trata dominantemente, como vimos, de estudos que tomam a relação Estado e sociedade diante dos reclames sociais pela garantia e/ou ampliação do direito à educação.

Enfim, com esse panorama, há um conjunto de desafios que se apresentam para a (metodologia da) pesquisa no campo. Em especial, ressalta-se: a) a necessidade de análises que tomem os processos de tomada de decisões e, antes, de constituição da agenda política, e os coteje aos processos de implantação/ tradução e resultados da política, ou seja, carece-se de estudos de acompanhamento e monitoramento com vistas a leituras do movimento da política; b) a importância da ampliação das revisões da literatura, especialmente para o exterior, com o intuito de colocar em diálogo os achados de pesquisa; c) a falta de estudos que tomem metodologias bem delineadas no exterior (ou mesmo no Brasil) e as utilizem adaptadamente à conjuntura nacional, o que potencializaria a amplitude das conclusões, mesmo em casos de estudos de caso, ou de políticas locais; d) a necessidade de se pensar melhor sobre a definição a priori das teorias. Vale dizer, no campo há estudos que apresentam um viés muito determinista em relação à política, perdendo a noção de contradição e fluidez que lhe é inerente, revelando, por vezes, a decorrente dificuldade que pesquisadores do campo têm em tomar a teoria como hipótese (BRANDÃO, 2002). Assim, encontram-se estudos que optam por dada base teórica, a qual nem sempre é a mais indicada para a lida com a empiria em questão; e) por fim, a importância de os pesquisadores todos não pararem de fazer política e análises políticas; entretanto, deve-se priorizar a pesquisa sobre políticas educacionais e avaliações da política, até para se ter mais respaldo para a própria ação política. 


\section{Referências}

ANPED. Associação Nacional de Pesquisa e Pós-Graduação em Educação. (Base de dados dos trabalhos aprovados/apresentados nas sessões anuais). Disponível em: <www.anped.org. br>. Acesso em: out. 2012.

BALL, S. J. Education policy and social class. Londres: Routledge, 2006a.

BALL, S. J. Sociologia das políticas educacionais e pesquisa crítico-social: uma revisão pessoal das políticas educacionais e da pesquisa em política educacional. Currículo Sem Fronteiras, v. 6, n. 2, p. 10-32, jul./dez. 2006b.

BALL, S. J.; MAINARDES, J. Políticas educacionais: questões e dilemas. São Paulo: Cortez, 2011.

BRANDÃO, Z. A teoria como hipótese. In: BRANDÃO, Z. Pesquisa em educação: conversas com pós-graduandos. Rio de Janeiro: Ed. PUC-Rio \& Ed. Loyola, 2002. p. 61-72.

DRAIBE, S. M. Avaliação de Implementação: esboço de uma metodologia de trabalho em políticas públicas. In: BARREIRA, M. C. R.; CARVALHO, M. C. (Org.). Tendências e perspectivas na avaliação de políticas e programas sociais. São Paulo: IEI/PUCSP, 2001. p. 13-42.

FIGUEIREDO, A. M. C.; FIGUEIREDO, M. F. Avaliação política e avaliação de políticas: um quadro de referência teórico. São Paulo: IDESP, 1986.

MULLER, P.; SUREL, Y. A análise das políticas públicas. Tradução de Agemir Bavaresco e Alceu R. Ferraro. Pelotas: EUCAT, 2002.

NEGT, O.; KLUGE, A. O que há de político na política. São Paulo: Ed. UNESP, 1999.

SOUZA, A. R. A natureza política da gestão escolar e as disputas pelo poder na escola. Revista Brasileira de Educação, Rio de Janeiro, v. 17, n. 49, p. 159-174, jan./abr. 2012. DOI: 10.1590/S1413-24782012000100009

Recebido em 30/11/2014

Versão final recebida em 13/04/2014

Aceito em 17/04/2014 